\title{
Certified Kitchen Managers: Do They Improve Restaurant Inspection Outcomes? ${ }^{\dagger}$
}

\author{
SHERYL C. CATES, ${ }^{1 *}$ MARY K. MUTH, ${ }^{1}$ SHAWN A. KARNS, ${ }^{1}$ MICHAEL A. PENNE, ${ }^{1}$ CARMILY N. STONE, ${ }^{2}$ \\ JUDY E. HARRISON, ${ }^{3}$ AND VINCENT J. RADKE ${ }^{4}$ \\ ${ }^{1}$ RTI International, 3040 Cornwallis Road, P.O. Box 12194, Research Triangle Park, North Carolina 27709; ${ }^{2}$ Iowa Department of Public Health, \\ Bureau of Environmental Health Services, Division of Environmental Health and ${ }^{3}$ Iowa Department of Inspections and Appeals, \\ Food and Consumer Safety Bureau, 321 East 12th Street, Des Moines, Iowa 50319; and ${ }^{4}$ Centers for Disease Control and Prevention, \\ National Center for Environmental Health, 4770 Buford Highway, Northeast, Atlanta, Georgia 30341, USA
}

MS 08-201: Received 1 May 2008/Accepted 26 August 2008

\begin{abstract}
Restaurants are associated with a significant number of foodborne illness outbreaks in the United States. Certification of kitchen managers through an accredited training and testing program may help improve food safety practices and thus prevent foodborne illness. In this study, relationships between the results of routine restaurant inspections and the presence of a certified kitchen manager (CKM) were examined. We analyzed data for 4,461 restaurants in Iowa that were inspected during 2005 and 2006 (8,338 total inspections). Using logistic regression analysis, we modeled the outcome variable $(0=$ no critical violations $[\mathrm{CVs}] ; 1=$ one or more CVs) as a function of presence or absence of a CKM and other explanatory variables. We estimated separate models for seven inspection categories. Restaurants with a CKM present during inspection were less likely to have a CV for personnel $(P<0.01)$, food source or handling $(P<0.01)$, facility or equipment requirements $(P<0.05)$, warewashing $(P<0.10)$, and other operations $(P<0.10)$. However, restaurants with a CKM present during inspection were equally likely to have a $\mathrm{CV}$ for temperature or time control and plumbing, water, or sewage as were restaurants without a CKM present. Analyses by type of violation within the temperature and time control category revealed that restaurants with a CKM present during inspection were less likely to have a CV for hot holding $(P<0.05)$, but the presence of a CKM did not affect other types of temperature and time control violations. Our analyses suggest that the presence of a CKM is protective for most types of CVs, and we identify areas for improving training of CKMs.
\end{abstract}

Food prepared outside of the home is a significant source of foodborne illness in the United States (15). Of the 9,040 foodborne disease outbreaks reported to the Centers for Disease Control and Prevention (CDC) from 1998 to $2004,52 \%$ were associated with food service establishments, including restaurants, delicatessens, cafeterias, and hotels (15). Case-control studies conducted by the CDC Foodborne Diseases Active Surveillance Network (FoodNet) and other researchers have revealed significant associations between eating food prepared outside the home and an increased risk of foodborne illness. For example, in a study of persons infected with Escherichia coli O157:H7, eating at a table-service restaurant was a risk factor for infection (17), in a study of people infected with Salmonella Enteritidis, consumption of eggs prepared outside of the home was a risk factor for infection (18), and in a study of people infected with Campylobacter, consumption of chicken prepared at a restaurant was a risk factor for infection (24).

Many Americans consume meals prepared outside the home. In 2006, Americans spent $\$ 529$ billion on food consumed outside the home (26), nearly one-half of the money

\footnotetext{
* Author for correspondence. Tel:(919-541-6810; Fax: 919-541-6683; E-mail: scc@rti.org.

$\dagger$ The findings and conclusions in this manuscript are those of the authors and do not necessarily represent the views of the Centers for Disease Control and Prevention.
}

spent on food in the United States (27). On average, one of five meals consumed by Americans ( 4.2 meals per week) is prepared outside the home (9).

Two previous studies revealed that unsafe food handling practices are common in restaurants. A telephone survey revealed that risky food preparation practices were commonly reported by respondents who worked in restaurants (11). Sixty percent of respondents did not always wear gloves while touching ready-to-eat food, $23 \%$ did not always wash their hands between handling raw meat and handling ready-to-eat food, $33 \%$ did not change their gloves between handling raw meat and handling ready-to-eat food, $53 \%$ did not use a thermometer to check food temperatures, and 5\% had worked while ill with vomiting or diarrhea. In a study conducted by the U.S. Food and Drug Administration (FDA), $64 \%$ of full-service restaurants and $42 \%$ of fast food restaurants did not follow recommended practices for proper holding or time and temperature control, and $42 \%$ of full-service restaurants and $31 \%$ of fast food restaurants did not follow recommended practices for personnel hygiene for food workers (28).

Bryan (2) identified several factors that have a positive impact on food safety in the retail food environment. These factors include inspections by local or state inspectors, knowledge of the FDA Food Code (29), and adequate training of food workers and managers. The FDA Food Code does not mandate food safety certification but does recog- 
nize certification by an accredited program as one means by which a person in charge can demonstrate knowledge of foodborne illness prevention methods, how to apply hazard analysis and critical control point principles, and how to meet the requirements of the Food Code. Specific requirements differ among states, but in general to become certified an individual must take a training class and pass one of the three exams accredited by the Conference for Food Protection-American National Standards Institute (1).

In several studies, the relationship between certified kitchen managers (CKMs) and restaurant inspection scores as a proxy measure for food safety has been examined. Some researchers suggested that the presence of a CKM improves restaurant inspection scores $(7,19,22)$, whereas other researchers found no relationship $(5,6,30)$. In these studies, inspection scores were compared before and after the implementation of a training and certification program. Most of these studies were conducted several years ago, and thus the results may be less relevant to current restaurant inspection practices. Some of the studies with experimental designs did not include a control group, so it is difficult to determine whether the positive impact was due to training or to other factors. For most of these studies, the sample size was very small and the study was limited to a specific county, city, or restaurant chain.

In 2006, Hedberg et al. (12) found that the presence of a CKM had a protective effect with respect to foodborne illness outbreaks. Thus, the presence of a CKM may help to improve food safety practices among food workers and ultimately reduce foodborne illness.

The purpose of the present study was to examine the relationship between restaurant inspection results, specifically the occurrence of critical violations, and the presence of a CKM. A critical violation describes a situation that if left uncorrected is more likely than other violations to contribute to food contamination, illness, or an environmental health hazard. We estimated logistic regression models to determine whether the presence of a CKM decreases the likelihood of the occurrence of critical violations by inspection category (e.g., food temperature and time control or personnel). We conducted the analysis using recent inspection data for the state of Iowa, where food safety certification of kitchen managers is recommended but not mandated. Unlike previous studies, our analysis was state wide and employed regression modeling techniques so that we could attribute the occurrence of specific types of critical violations to the presence of a CKM.

\section{MATERIALS AND METHODS}

Iowa inspection procedures. Responsibility for restaurant food safety in Iowa is shared by the Iowa Department of Inspections and Appeals (DIA), which conducts routine and other types of restaurant inspections, and the Iowa Department of Public Health, which investigates foodborne disease outbreaks. The DIA has a joint state and local inspection program for restaurants and other establishments where food is served, such as schools, nursing homes, and hospitals. DIA inspectors conduct inspections in 20 counties (inspecting about half of all food establishments in the state), and under contract to the DIA, inspectors from 30 local

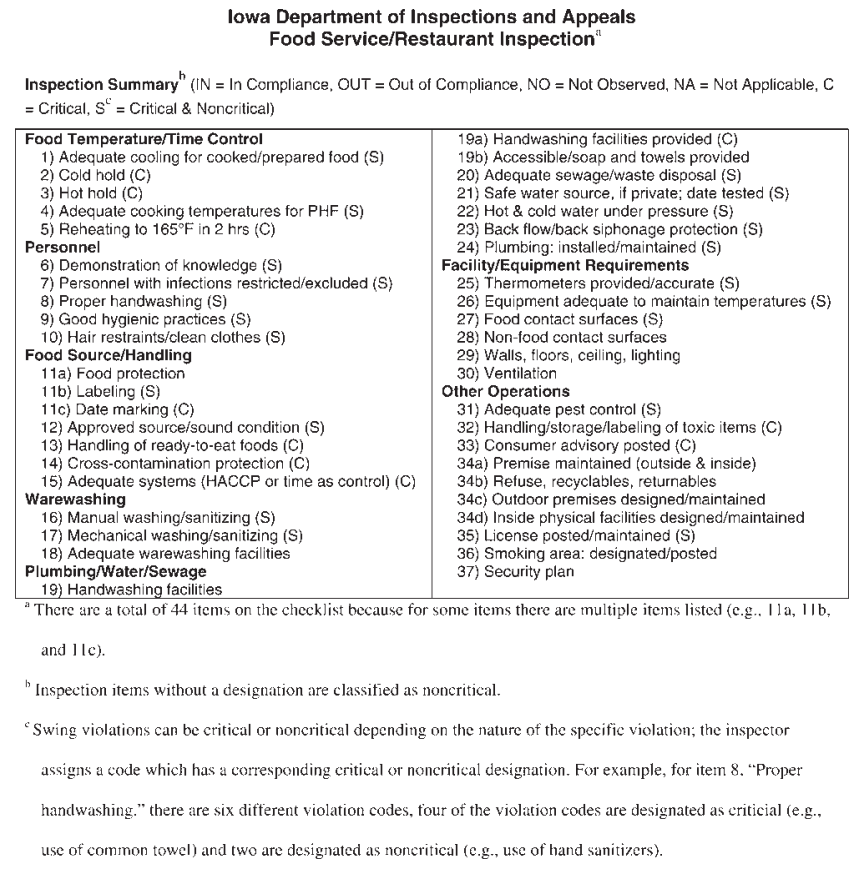

FIGURE 1. Inspection form for the state of Iowa.

health departments conduct inspections in 79 counties and five municipalities. Both the DIA inspectors and contract inspectors are sanitarians or environmental health officers. The DIA monitors the contract agencies to ensure that their inspections are consistent with implementation of the Iowa Food Code (13).

The Iowa Food Code requires that all food establishments be inspected at least once every 6 months or according to a riskbased inspection process. Under the risk-based inspection process, restaurants that prepare and serve a wide variety of foods to a large number of people on a daily basis are inspected more frequently than are limited-service food service establishments that sell only prepackaged food items. A high-risk establishment may be inspected up to three times each year, whereas a low-risk establishment may be inspected only once each year. According to the restaurant inspection data, most restaurants are inspected about once per year.

During a routine inspection, inspectors use a 44-point checklist (see Fig. 1) to assess whether the establishment is conforming to the Iowa Food Code. With the exception of the "no bare hand contact with ready-to-eat foods" requirement, Iowa has adopted the 1997 FDA Food Code. The checklist items are grouped by seven inspection categories: food temperature and time control; personnel; food source and handling; warehousing; plumbing, water, and sewage; facility and equipment requirements; and other operations. Within each category, violations associated with different items are designated as critical violations, noncritical violations, or swing violations. Swing violations can be critical or noncritical depending on the nature of the specific violation; the inspector assigns a violation code that has a corresponding critical or noncritical designation. For example, for item 8, "Proper handwashing," there are six different violation codes, four of the violation codes are designated as critical (e.g., use of common towel) and two are designated as noncritical (e.g., use of hand sanitizers). Critical violations must be corrected within 10 days of the original inspection, and noncritical items must be corrected within 90 days. Of the 44 checklist items, 10 are critical violations, 20 are swing violations, and 14 are noncritical violations.

For routine inspections, an inspection report is prepared that indicates whether the establishment is in compliance (IN) or out 
TABLE 1. Summary of Iowa inspection data, 2005 and 2006

\begin{tabular}{|c|c|c|c|c|}
\hline Factor $^{a}$ & $\begin{array}{l}\text { Restaurants } \\
\text { with liquor }\end{array}$ & $\begin{array}{l}\text { Restaurants } \\
\text { without liquor }\end{array}$ & $\begin{array}{l}\text { Taverns } \\
\text { with food }\end{array}$ & $\begin{array}{c}\text { All } \\
\text { establishments }\end{array}$ \\
\hline No. of establishments & 1,309 & 2,535 & 617 & 4,461 \\
\hline No. of routine inspections & 2,458 & 4,784 & 1,096 & 8,338 \\
\hline Avg no. of inspections ${ }^{b}$ & 1.9 & 1.9 & 1.8 & 1.9 \\
\hline No. of establishments with at least one CV & 1,131 & 1,942 & 454 & 3,527 \\
\hline Total no. of CVs & 5,092 & 6,899 & 1,453 & 13,444 \\
\hline Avg no. of $\mathrm{CVs}^{c}$ & 3.9 & 2.7 & 2.4 & 3.0 \\
\hline $\begin{array}{l}\text { Avg no. of CVs among establishments with at least one } \\
\text { violation }^{d}\end{array}$ & 4.5 & 3.6 & 3.2 & 3.8 \\
\hline No. of establishments with CKM for at least one inspection & 381 & 768 & 43 & 1,192 \\
\hline \% establishments with CKM for at least one inspection & 29.1 & 30.3 & 7.0 & 26.7 \\
\hline No. of inspections with CKM & 556 & 1,143 & 59 & 1,758 \\
\hline$\%$ inspections with CKM & 22.6 & 23.9 & 5.4 & 21.1 \\
\hline
\end{tabular}

${ }^{a} \mathrm{CV}$, critical violation; CKM, certified kitchen manager.

${ }^{b}$ Number of routine inspections/number of establishments.

${ }^{c}$ Total number of $\mathrm{CVs} /$ number of establishments.

${ }^{d}$ Total number of $\mathrm{CV}$ s/number of establishments with at least one $\mathrm{CV}$.

of compliance (OUT) with each item on the checklist and whether any items were not observed (NO) by the inspector or were not applicable (NA) to the inspected food establishment. When the establishment is out of compliance, then the inspection report indicates whether each violation is critical or noncritical. Inspection reports are collected electronically by the DIA and its contractors and are transmitted to the DIA. A final score or rating (e.g., 95 or A) is not assigned.

Each inspection report also documents whether the person in charge at the time of the inspection is a CKM. The person in charge at the time of inspection is required to "demonstrate knowledge by compliance with the (Iowa Food) Code, by being a certified food protection manager who has shown proficiency of required information through passing a test that is part of an accredited program, or by responding correctly to the inspector's questions as they relate to the specific food operation" (13). The Iowa Restaurant Association, the Iowa DIA, and Iowa State University extension field specialists provide food safety certification and testing. The State of Iowa recognizes only those food safety certification and testing courses that are approved by the Conference on Food Protection.

Analysis data set. We analyzed routine inspection records for 2005 and 2006 for three types of food service establishments in Iowa: (i) restaurants that serve liquor (the majority of sales are for food, however alcoholic beverages also are served for consumption with meals on the premises; (ii) restaurants that do not serve liquor (licensed food establishments that do not have a liquor license); and (iii) taverns with food preparation (establishments whose main business is on-site consumption of alcoholic beverages but that also have a limited food menu). An establishment was included in the data set when it had at least one routine inspection during 2005 or 2006 . Other types of inspections (preinspections before opening, rechecks, complaints, and foodborne illness investigations) were excluded from the data set.

To prepare the analysis data set, we imputed values for records with missing data using other information available for the record in the data set. For records with missing information on service type (fast food versus full service) $(n=416)$, we were able to assign the service type for well-known national and regional chains based on the name of the establishment. In other cases, we conducted Internet searches or assigned the service type based on words in the name of the establishment (e.g., establishments with "diner" in the name were classified as full service). For one county, the records were missing information on whether swing items were critical or noncritical $(n=857)$. For these records, we reviewed the inspection notes to determine the nature of the violation to assign a code with a corresponding critical or noncritical designation. The total number of usable inspection records was 8,338 , and the number of food service establishments was 4,461 .

Table 1 provides a summary of the Iowa inspection data (2005 and 2006) by type of establishment. Of the 4,461 establishments in the data set, 3,527 (79\%) had at least one critical violation during 2005 and 2006. The total number of critical violations for this 2-year period was 13,444 . On average, restaurants that serve liquor had 3.9 critical violations across all inspections, restaurants that do not serve liquor had 2.7 critical violations, and taverns with food preparation had 2.4 critical violations. A CKM was present during at least one inspection at $29 \%$ of restaurants that serve liquor, $30 \%$ of restaurants that do not serve liquor, and $7 \%$ of taverns with food preparation. The percentage of inspections with a CKM present was lower than the percentage of establishments with a CKM present because some establishments had a CKM present for some but not all inspections.

Table 2 gives the number and percentage of inspections with at least one critical violation listed by inspection category across all establishment types. The occurrence of at least one critical violation was most prevalent for facility and equipment requirements $(33 \%)$ and food source and handling (31\%) and was least prevalent for warewashing $(9 \%)$.

Logistic regression analysis. We estimated a series of regression models in which we defined the outcome variable for the analysis as a dichotomous variable: $0=$ no critical violations, and $1=$ one or more critical violations. We modeled the outcome variable as a function of whether the person in charge at the time of inspection was a CKM. We considered modeling the outcome variable as whether the establishment had a CKM present for at least one inspection during the time period of the data set; however, we could not consistently classify establishments because there was only one inspection record for many establishments.

We included the following explanatory variables in the analysis: year of inspection (2005 or 2006), type of inspector (DIA or 
TABLE 2. Number and percentage of inspections with at least one critical violation (CV) by inspection category, 2005 and 2006

\begin{tabular}{lrrr}
\hline & & \multicolumn{2}{c}{$\begin{array}{c}\text { Inspections with at } \\
\text { least one CV }\end{array}$} \\
\cline { 3 - 5 } \multicolumn{1}{c}{ Inspection category } & $\begin{array}{c}\text { No. of } \\
\text { inspections }\end{array}$ & No. & $\%$ \\
\hline Food temp and time control & 8,139 & 1,832 & 22.5 \\
Personnel & 8,296 & 1,178 & 14.2 \\
Food source and handling & 8,276 & 2,569 & 31.0 \\
Warewashing & 7,314 & 690 & 9.4 \\
Plumbing, water, and sewage & 8,337 & 1,108 & 13.3 \\
Facility and equipment require- & 8,333 & 2,709 & 32.5 \\
$\quad$ ments & & & \\
Other operations & 8,335 & 1,814 & 21.8 \\
\hline
\end{tabular}

${ }^{a}$ The number of inspections for each inspection category differs because inspections were excluded from the analysis when the inspection items were not observed or were not applicable for that inspection.

contractor), establishment type (restaurant that serves liquor, restaurant that does not serve liquor, or tavern with food preparation), annual revenue (categorical variable with five levels), and type of service (full service or fast food). We estimated a model for all inspection categories combined and separate models for each of the seven inspection categories. All analyses were conducted using SUDAAN, release 9 (23), which corrects the variance estimation to account for the correlations resulting from establishments with multiple inspections in the data set.

Table 3 shows the values for the explanatory variables included in the logistic regression model. A CKM was present during $21 \%$ of inspections. Fifty-five percent of inspections were conducted in 2005 , and $36 \%$ of inspections were conducted by DIA inspectors. Fifty-seven percent of inspections were for restaurants that do not serve liquor, $30 \%$ were for restaurants that serve liquor, and $13 \%$ were for taverns with food preparation. More than half of the inspections were for establishments with annual revenue greater than $\$ 250,000$. Seventy percent of inspections were for full-service establishments.

\section{RESULTS}

Table 4 reports the odds ratios (ORs) and the significance of the $P$ values for the $t$ test $(P>|t|)$ for the logistic regression model estimated for all inspection categories combined and for the models estimated individually for each of the seven inspection categories. An OR of less than 1 indicates that an establishment was less likely to have a critical violation in that category, whereas an OR of greater than 1 indicates that an establishment was more likely to have a critical violation in that category. For all inspection categories combined, establishments with a CKM present during inspection were less likely to have a critical violation $(\mathrm{OR}=0.82, P<0.01)$. Establishments with a CKM present during inspection were less likely to have a critical violation for personnel ( $\mathrm{OR}=0.73, P<0.01$ ), food source and handling $(\mathrm{OR}=0.80, P<0.01)$, warewashing (OR $=0.82, P<0.10)$, facility and equipment requirements $(\mathrm{OR}=0.85, P<0.05)$, and other operations $(\mathrm{OR}=0.87$, $P<0.10)$. However, establishments with a CKM present during inspection were equally likely to have a critical violation for food temperature and time control and for
TABLE 3. Values for model variables $(\mathrm{n}=8,338)$

\begin{tabular}{|c|c|}
\hline Variable & $\%$ \\
\hline \multicolumn{2}{|c|}{ CKM present during inspection } \\
\hline Yes & 21.1 \\
\hline No & 78.9 \\
\hline \multicolumn{2}{|l|}{ Year of inspection } \\
\hline 2005 & 54.7 \\
\hline 2006 & 45.3 \\
\hline \multicolumn{2}{|l|}{ Type of inspector } \\
\hline DIA & 35.8 \\
\hline Contractor & 64.2 \\
\hline \multicolumn{2}{|l|}{ Establishment type } \\
\hline Restaurant with liquor & 29.5 \\
\hline Restaurant without liquor & 57.4 \\
\hline Tavern with food & 13.1 \\
\hline \multicolumn{2}{|l|}{ Revenue } \\
\hline$\leq \$ 50,000$ & 12.7 \\
\hline$\$ 50,001-100,000$ & 12.2 \\
\hline$\$ 100,001-250,000$ & 20.3 \\
\hline$\$ 250,001-500,000$ & 12.8 \\
\hline$>\$ 500,000$ & 42.0 \\
\hline \multicolumn{2}{|l|}{ Service type } \\
\hline Full service & 70.2 \\
\hline Fast food & 29.8 \\
\hline
\end{tabular}

plumbing, water, and sewage as were establishments without a CKM present.

The other explanatory variables included in the models were significant for the overall model $(P<0.01)$ and for some inspection categories. Establishments that serve liquor were more likely than taverns with food preparation to have a critical violation for food temperature and time control, personnel, food source and handling, warewashing, and other operations $(P<0.05)$. Establishments that do not serve liquor were more likely than taverns with food preparation to have a critical violation for food temperature and time control, personnel, food source and handling, and plumbing, water, and sewage $(P<0.01)$. Full-service establishments were more likely than fast food establishments to have a critical violation for food temperature and time control, personnel, food source and handling, warewashing, and facility and equipment requirements $(P<0.01)$. These results also suggest that establishments with higher annual revenues were more likely than establishments with lower annual revenues to have a critical violation for most inspection categories.

Food temperature and time control is an important risk factor associated with foodborne illness outbreaks (28). Because critical violations for food temperature and time control were equally likely at establishments with a CKM present and at those without a CKM, we conducted analyses by inspection item for the food temperature and time control inspection category to further explore this relationship. Table 5 shows the number and percentage of inspections with at least one critical violation for the food temperature and time control inspection category. The occurrence of at 
TABLE 4. Likelihood of at least one critical violation during a routine inspection

\begin{tabular}{|c|c|c|c|c|c|c|c|c|}
\hline \multirow[b]{2}{*}{ Variable } & \multicolumn{8}{|c|}{ Odds ratios $^{a}$} \\
\hline & $\begin{array}{c}\text { All categories } \\
(n=8,338)\end{array}$ & $\begin{array}{l}\text { Food temp, } \\
\text { time control } \\
(n=8,139)\end{array}$ & $\begin{array}{l}\text { Personnel } \\
(n=8,296)\end{array}$ & $\begin{array}{l}\text { Food source, } \\
\text { handling } \\
(n=8,276)\end{array}$ & $\begin{array}{l}\text { Warewashing } \\
(n=7,314)\end{array}$ & $\begin{array}{l}\text { Plumbing, } \\
\text { water, sewage } \\
(n=8,337)\end{array}$ & $\begin{array}{l}\text { Facility, } \\
\text { equipment } \\
\text { requirements } \\
(n=8,333)\end{array}$ & $\begin{array}{c}\text { Other } \\
\text { operations } \\
(n=8,335)\end{array}$ \\
\hline $\begin{array}{l}\text { Certified kitchen manager (ref- } \\
\text { erence }=\text { no) }\end{array}$ & $0.82 * * *$ & 0.99 & $0.73 * * *$ & $0.80 * * *$ & $0.82 *$ & 0.95 & $0.85 * *$ & $0.87 *$ \\
\hline $\begin{array}{l}\text { Year of inspection (reference } \\
\quad=2006)\end{array}$ & $0.86 * * *$ & $1.11^{*}$ & $0.84 * * *$ & 0.97 & 0.90 & 0.93 & 0.98 & $0.82 * * *$ \\
\hline $\begin{array}{l}\text { Type of inspector (reference } \\
=\text { contractor) }\end{array}$ & $0.81 * * *$ & 0.95 & $0.88^{*}$ & $1.25 * * *$ & 1.08 & $0.72 * * *$ & $0.57 * * *$ & $0.77 * * *$ \\
\hline \multicolumn{9}{|c|}{ Establishment type $($ reference $=$ tavern $)$} \\
\hline Restaurant with liquor & $1.76 * * *$ & $3.34 * * *$ & $1.59 * * *$ & $1.68 * * *$ & $1.46^{* *}$ & 1.08 & 1.16 & $1.47 * * *$ \\
\hline Restaurant without liquor & $1.27 * * *$ & $3.36 * * *$ & $1.41 * * *$ & $1.36 * * *$ & 1.24 & $0.73 * * *$ & 0.88 & 1.11 \\
\hline \multicolumn{9}{|l|}{ Revenue (reference $>\$ 500,000$ ) } \\
\hline$\leq \$ 50,000$ & $0.30 * * *$ & $0.32 * * *$ & $0.36 * * *$ & $0.57 * * *$ & $0.73^{*}$ & $0.49 * * *$ & $0.32 * * *$ & $0.54 * * *$ \\
\hline$\$ 50,001-100,000$ & $0.53 * * *$ & $0.40 * * *$ & $0.59 * * *$ & $0.85 *$ & $0.72 * *$ & $0.59 * * *$ & $0.43 * * *$ & $0.72 * * *$ \\
\hline$\$ 100,001-250,000$ & $0.64 * * *$ & $0.58 * * *$ & $0.69 * * *$ & 0.98 & 0.83 & $0.60 * * *$ & $0.58 * * *$ & $0.70 * * *$ \\
\hline$\$ 250,001-500,000$ & $0.79 * * *$ & $0.80 * *$ & $0.83 *$ & 0.94 & $0.68 * * *$ & $0.66 * * *$ & $0.80 * *$ & 0.92 \\
\hline $\begin{array}{l}\text { Service type (reference }=\text { fast } \\
\text { food) }\end{array}$ & $1.44 * * *$ & $1.83 * * *$ & $1.47 * * *$ & $2.48 * * *$ & $1.34 * *$ & 1.08 & $1.35 * * *$ & 1.12 \\
\hline
\end{tabular}

$a * * * P<0.01 ; * * P<0.05 ; * P<0.10$.

least one critical violation was most prevalent for cold hold (17\% of inspections) and least prevalent for adequate cooking of potentially hazardous food $(0.4 \%)$.

Table 6 gives the ORs and the significance of the $P$ values for the $t$ test $(P>|t|)$ for the logistic regression model estimated for the food temperature and time control inspection category and for the models estimated for each inspection item. Restaurants with a CKM present during inspection were less likely to have a critical violation for hot hold, i.e., not maintaining potentially hazardous foods at $140^{\circ} \mathrm{F}$ or above $(\mathrm{OR}=0.75, P<0.05)$, but the presence of a CKM did not have a significant effect on violations for the other inspection items.

TABLE 5. Number and percentage of inspections with at least one critical violation $(\mathrm{CV})$ for the food temperature and time control inspection items, 2005 and 2006

\begin{tabular}{lrrr}
\hline & & \multicolumn{2}{c}{$\begin{array}{c}\text { Inspections with at } \\
\text { least one CV }\end{array}$} \\
\cline { 3 - 5 } \begin{tabular}{c} 
Inspection item \\
\cline { 3 - 4 }
\end{tabular} & $\begin{array}{c}\text { No. of } \\
\text { inspections }\end{array}$ & No. & $\%$ \\
\hline $\begin{array}{l}\text { Adequate cooling for cooked or } \\
\text { prepared food }\end{array}$ & 3,379 & 151 & 4.5 \\
$\begin{array}{l}\text { Cold hold } \\
\text { Hot hold }\end{array}$ & 7,999 & 1,337 & 16.7 \\
$\begin{array}{l}\text { Adequate cooking temp for po- } \\
\text { tentially hazardous food }\end{array}$ & 5,857 & 510 & 8.7 \\
Reheating to $165^{\circ} \mathrm{F}$ in 2 $\mathrm{h}$ & 2,366 & 20 & 0.4 \\
\hline
\end{tabular}

${ }^{a}$ The number of inspections for each inspection item differs because inspections were excluded from the analysis when the inspection items were not observed or were not applicable for that inspection.

\section{DISCUSSION}

In 2002, 16 states had state-mandated food safety certification requirements for restaurants, and several states were considering adopting legislation that would require food safety certification for food service workers; food safety certification is voluntary in the remaining states (25). The results of the present analysis suggest that the presence of a CKM is protective for most types of critical violations. In particular, CKMs were associated with a lower likelihood of violations for personnel, food source and handling, and facility and equipment requirements and to a lesser extent for warewashing and other operations. These findings suggest that kitchen managers who have successfully completed a food safety training and certification program are knowledgeable about the relationship between foodborne illness risk factors and safe food handling and preparation practices and thus may be more likely to follow and enforce recommended practices to control foodborne illness risk factors. The presence of a CKM also likely improves the quality of informal on-the-job training on which many restaurants rely, thus increasing adherence to recommended food handling and preparation practices among food workers (12). The study results suggest that improvements are needed in the areas of plumbing, water, and sewage and food temperature and time control. The plumbing-watersewage inspection category mainly comprises control measures pertaining to the availability and proper operation of equipment such as adequate sewage and waste disposal and back flow and back siphonage protection. Certification training addresses these physical facility issues, and it is the responsibility of kitchen managers to notify establishment owners when problems occur in these areas. However, 
TABLE 6. Likelihood of having at least one critical violation by food temperature and time control inspection item

\begin{tabular}{|c|c|c|c|c|c|c|}
\hline \multirow[b]{2}{*}{ Variable } & \multirow[b]{2}{*}{$\begin{array}{l}\text { Food temp, } \\
\text { time control } \\
(n=8,139)\end{array}$} & \multicolumn{5}{|c|}{ Odds ratios $^{a}$} \\
\hline & & $\begin{array}{l}\text { Adequate cooling } \\
\text { for cooked, } \\
\text { prepared food } \\
(n=3,379)\end{array}$ & $\begin{array}{l}\text { Cold hold } \\
(n=7,999)\end{array}$ & $\begin{array}{l}\text { Hot hold } \\
(n=5,857)\end{array}$ & $\begin{array}{l}\text { Adequate cooking } \\
\text { temp for PHF } \\
(n=4,366)\end{array}$ & $\begin{array}{l}\text { Reheating } \\
(n=2,777)\end{array}$ \\
\hline $\begin{array}{l}\text { Certified kitchen manager (refer- } \\
\text { ence }=\text { no) }\end{array}$ & 0.99 & 0.98 & 1.08 & $0.75 * *$ & 1.26 & 0.86 \\
\hline $\begin{array}{l}\text { Year of inspection (reference }= \\
\text { 2006) }\end{array}$ & $1.11 *$ & 0.76 & $1.16^{* *}$ & 0.88 & $0.43 *$ & 0.77 \\
\hline $\begin{array}{l}\text { Type of inspector (reference }= \\
\text { contractor) }\end{array}$ & 0.95 & $1.98 * * *$ & $0.82 * * *$ & $1.21 *$ & 1.41 & $1.55 * * *$ \\
\hline \multicolumn{7}{|l|}{ Establishment type $($ reference $=$ tavern $)$} \\
\hline Restaurant with liquor & $3.34 * * *$ & $3.79 * * *$ & $3.01 * * *$ & $2.39 * * *$ & 1.38 & 1.31 \\
\hline Restaurant without liquor & $3.36 * * *$ & $2.27 *$ & $2.94 * * *$ & $2.44 * * *$ & 0.66 & 0.84 \\
\hline \multicolumn{7}{|l|}{ Revenue (reference $>\$ 500,000$ ) } \\
\hline$\leq \$ 50,000$ & $0.32 * * *$ & $0.24 * * *$ & $0.37 * * *$ & 0.79 & 0.56 & 0.60 \\
\hline$\$ 50,001-100,000$ & $0.40 * * *$ & $0.49 * *$ & $0.38 * * *$ & $0.67 *$ & NA & 0.65 \\
\hline$\$ 100,001-250,000$ & $0.58 * * *$ & 0.65 & $0.57 * * *$ & 0.88 & 0.43 & 1.06 \\
\hline$\$ 250,001-500,000$ & $0.80 * *$ & 0.98 & $0.82 * *$ & $0.71 * *$ & 0.27 & 1.22 \\
\hline Service type (reference $=$ fast food $)$ & $1.83 * * *$ & $3.39 * * *$ & $1.85 * * *$ & $1.42 * *$ & 0.61 & $1.83 * * *$ \\
\hline
\end{tabular}

${ }^{a}$ PHF, potentially hazardous food; NA, not applicable (no restaurants in this category received a critical violation for adequate cooking temp for PHF). *** $P<0.01$; ** $P<0.05$; $* P<0.10$.

kitchen managers may have limited control over this inspection category because some measures may require capital investment by establishment owners.

The presence of a CKM was not protective for food temperature and time control violations. Following recommended temperature and time controls for potentially hazardous food can help destroy, reduce, or slow the growth of foodborne pathogens; thus, adherence to these recommendations is particularly important for reducing the risk of foodborne illness outbreaks. Analyses by type of violation within the food temperature and time control category revealed that restaurants with a CKM present during inspection were less likely to have a critical violation for hot holding, but the presence of a CKM did not have an effect on adequate cooling for cooked and prepared food, cold holding, adequate cooking temperatures for potentially hazardous food, or for reheating of foods to $165^{\circ} \mathrm{F}$ within $2 \mathrm{~h}$ (i.e., reheating of potentially hazardous foods for hot holding must be done rapidly, and the reheating time must not exceed $2 \mathrm{~h}$ ). The presence of a CKM may have an effect on hot holding but not cold holding because hot holding is easier to accomplish because a broader temperature range is acceptable for hot holding than for cold holding. Hot holding also typically occurs for a limited period of time (e.g., during the lunch hour), whereas cold holding is ongoing. Thus, it may be easier for kitchen managers to pay more attention to hot-holding practices. Data were not available on the type of appliance for which the inspector measured the temperature (e.g., storage refrigeration unit versus salad bar) or the specific type of thermometer used; thus, we cannot assess whether these factors have an effect on the occurrence of critical violations.

As for plumbing-water-sewage violations, violations in cold holding and adequate cooling for cooked and prepared food could be due to inadequate or poorly operating equipment over which kitchen managers may have limited control. Although proper food temperature and time control is addressed in the food certification training and accreditation program, this training does not appear to have a significant effect on eliminating these types of violations. Thus, our study findings suggest that knowledge of a recommended practice does not always translate into its adoption. Other researchers have reported similar findings among food service workers $(4,20,21)$. Additional research is needed to better understand the relationship between training of CKMs and food temperature and time control violations to reduce the occurrence of this type of violation. Understanding the relationship between proper holding temperatures and initiating control by requiring monitoring of temperatures by food workers must become part of the overall training and inspection process.

Our results suggest that the type of establishment also may affect the occurrence of critical violations. Large establishments (i.e., annual revenues $>\$ 500,000$ ) were more likely than small establishments (i.e., annual revenues $\leq$ $\$ 500,000)$ to have a critical violation for most inspection categories. Large establishments serve more consumers and thus have higher volumes than do smaller establishments, potentially increasing the likelihood of a critical violation occurring. However, based on these results we cannot conclude that larger establishments are at increased risk for foodborne illness outbreaks compared with smaller establishments. If data were available on the number of meals served at each restaurant, the number of critical violations could be adjusted by the number of meals served to determine whether the size of the establishment is associated 
with the number of critical violations on a per-meal basis. This type of analysis would allow us to better understand the relationship between restaurant size and the occurrence of critical violations.

Establishments that serve liquor and establishments that do not serve liquor were more likely than taverns with food preparation to have a critical violation for most inspection categories. Taverns with food preparation generally serve food that requires minimal preparation (e.g., reheating prepared foods), thus potentially decreasing the likelihood of a critical violation occurring. Full-service establishments were more likely than fast food establishments to have a critical violation for most inspection categories. Owners of fast food establishments frequently own more than one establishment (i.e., the establishment is part of a chain), in which case they may be more likely to have specific food safety procedures in place and to offer food safety training to employees, thus decreasing the likelihood of a critical violation occurring. Compared with fast food establishments, which have limited menus, full-service establishments are more likely to serve a wider variety of foods, thus potentially increasing the likelihood of a critical violation occurring.

Research conducted by the FDA also revealed that the presence of a CKM has a positive effect on the control of certain foodborne illness risk factors (28). For fast food restaurants, compliance with recommended practices for proper holding time and temperature and for protecting food, surfaces, and utensils from contamination was significantly higher among restaurants with a CKM than among restaurants without a CKM. For full-service restaurants, compliance with recommended practices for personal hygiene and for protecting food, surfaces, and utensils from contamination was significantly higher among restaurants with a CKM than among restaurants without a CKM. However, the FDA study did not consider the effect of other restaurant characteristics in its analysis.

In contrast to our study, other researchers have examined the relationship between the presence of a CKM and restaurant inspection results by comparing inspection scores before and after the implementation of training and certification programs (7). Kneller and Bierma (19) and Palmer et al. (22) found that restaurant inspection scores improved significantly in establishments whose managers attended training programs. However, neither study included a control group, so it is difficult to attribute the positive impact to a training program alone. Cotterchio et al. (7) found that kitchen managers who were required to attend a training and certification course significantly improved their inspection scores, whereas the mean inspection scores for the control group did not change significantly. Cook and Casey (6) studied the extent to which a training course affected inspection scores and found that both the treatment and control groups had significantly higher inspection scores after the course, which suggests that the training did not cause the observed improvement in inspection scores. Likewise, Wright and Feun (30) found that participation in a manager certification program did not produce overall significant differences between the control and treatment groups. Cling- man (5) employed a pre- and poststudy design with a control group of noncertified managers and found that both groups had significantly improved inspection scores, but the CKM group had more improvement than did the noncertified manager group. Clingman speculated that noncertified managers' scores increased from the initial to follow-up inspection because managers were told a follow-up inspection would be made and because of differences in gender, age, education, and experience between the treatment and control groups.

Other researchers have attempted to associate routine restaurant inspection scores with subsequent foodborne illness outbreaks (12). In Seattle-King County, WA, violations of temperature control of potentially hazardous food were most strongly associated with outbreaks (14). In Los Angeles County, CA, outbreaks were associated with incorrect storage of food, reuse of food, and any food protection violation (3). In Miami-Dade County, FL, the presence of vermin was associated with outbreaks (8). In Tennessee, Jones et al. (16) found no difference in mean inspection scores for restaurants with a reported outbreak compared with restaurants without a reported outbreak. Hedberg et al. (12) found that the presence of a CKM had a protective effect with respect to outbreaks: $71 \%$ of nonoutbreak restaurants had a CKM, whereas only $32 \%$ of outbreak restaurants had a CKM. The presence of a CKM also was associated with the absence of bare-hand contact with foods, fewer outbreaks of norovirus infection, and the absence of outbreaks linked to Clostridium perfringens (12).

Challenges faced by restaurants trying to reduce the risk of foodborne illness outbreaks include high turnover and a labor force comprising young, inadequately trained employees who lack an understanding of the food handling and preparation practices that should be followed to mitigate risk factors (15). Thus, kitchen managers have an important role in communicating to food workers information about recommended practices to reduce the risk of foodborne illness. In focus groups with food workers and managers, participants highlighted the importance of workers being taught why following recommended food handling and preparation practices is important, not just how to engage in those practices (10). CKMs may be more likely than kitchen managers who are not certified in food safety to effectively communicate such information to food workers.

Limitations of the present study include limited data on establishment characteristics and other factors. Our analysis did not address bias among inspectors, some of whom may be more likely to cite (or not cite) certain types of violations. Our analysis relied on inspection data for a particular time period; however, we do not have data on food safety practices and restaurant operations between inspection visits when food handling practices were not being observed. Our analysis also was limited to food service establishments in Iowa. With the exception of the "no bare hand contact with ready-to-eat foods" requirement, Iowa has adopted the 1997 FDA Food Code. The Association of Food and Drug Officials reported in June 2005 that 48 of 56 U.S. states and territories have adopted food codes pat- 
terned after one of the five versions of the Food Code, beginning with the 1993 edition (29). Although the exact inspection form used by other states may differ from that used in Iowa, the information collected is similar, especially with regard to the types of critical violations, because the inspection forms for most states are based on the Food Code. Additional research is needed to determine whether similar findings would hold true for other states, although few states maintain the types of data needed to conduct such an analysis. However, because the inspection system used by Iowa is similar to that used in other states, we would expect similar findings.

\section{ACKNOWLEDGMENTS}

The authors thank the following: Laura Green and Carol Selman (National Center for Environmental Health, CDC) for their assistance with the analysis design and their review of the draft manuscript; Michaela Coglaiti and Katherine Kosa (RTI International) for their assistance with data cleaning and coding; and the Environmental Health Specialist Network (EHS-Net), a network of federal and state environmental health specialists and epidemiologists working to better understand the causes and prevention of foodborne illness, for their assistance with study design. Specifically, we thank Lisa Bushnell (Connecticut), Lore Lee (Oregon), and Henry Blade (Rhode Island).

\section{REFERENCES}

1. Almanza, B. A., and M. S. Nesmith. 2004. Food safety certification regulations in the United States. J. Environ. Health 66:10-14.

2. Bryan, F. L. 2002. Where we are in retail food safety, how we got to where we are, and how do we get there? J. Environ. Health 65: 29-36.

3. Buchholz, U., G. Run, J. L. Kool, J. Fielding, and L. Mascola. 2002. A risk-based restaurant inspection system in Los Angeles County. $J$. Food Prot. 65:367-372.

4. Clayton, D., C. Griffith, P. Price, and A. Peters. 2002. Food handlers' beliefs and self-reported practices. Int. J. Environ. Health Res. 12: 25-39.

5. Clingman, C. D. 1976. Ohio evaluates effects of food certification training. J. Environ. Health 38:235-236.

6. Cook, C. C., and R. Casey. 1979. Assessment of a foodservice management sanitation course. J. Environ. Health 41:281-284.

7. Cotterchio, M., J. Gunn, T. Coffill, P. Tormey, and A. Barry. 1998. Effect of a manager training program on sanitary conditions in restaurants. Public Health Rep. 113:353-358.

8. Cruz, M. A., D. J. Katz, and J. A. Suarez. 2001. An assessment of the ability of routine restaurant inspections to predict food-borne outbreaks in Miami-Dade County, Florida. Am. J. Public Health 91: 821-823.

9. Ebbin, R. 2000. Americans' dining-out habits. Available at: http:// www.restaurant.Org/rusa/magArticle.cfm?ArticleID=138. Accessed 1 November 2007.

10. Green, L. R., and C. Selman. 2005. Factors impacting food workers' and managers' safe food preparation practices: a qualitative study. Food Prot. Trends 25:981-990.

11. Green, L. R., C. Selman, A. Banarjee, R. Marcus, C. Medus, F. J. Angulo, V. Radke, S. Buchanan, and EHS-Net Working Group. 2005. Food service workers' self-reported preparation practices: an EHS-Net study. Int. J. Hyg. Environ. Health 208:27-35.

12. Hedberg, C. W., S. J. Smith, E. Kirkland, V. Radke, T. F. Jones, C. A. Selman, and the EHS-Net Working Group. 2006. Systematic environmental evaluations to identify food safety differences between outbreak and nonoutbreak restaurants. J. Food Prot. 69:2697-2702.

13. Iowa Department of Inspections and Appeals. 2005. Food code.
Available at: http://dia.iowa.gov/food/Documents/1997FoodCode\% 2009.05.pdf. Accessed 1 November 2007.

14. Irwin, K., J. Ballard, J. Grendon, and J. Kobayashi. 1989. Results of routine restaurant inspections can predict outbreaks of foodborne illness: the Seattle-King County experience. Am. J. Public Health 79:586-590.

15. Jones, T. F., and F. J. Angulo. 2006. Eating in restaurants: a risk factor for foodborne disease. Clin. Infect. Dis. 14:1324-1328.

16. Jones, T. F., B. I. Pavlin, B. J. LaFleur, L. A. Ingram, and W. Schaffner. 2004. Restaurant inspection scores and foodborne disease. Emerg. Infect. Dis. 10:688-692.

17. Kassenborg, H. D., C. W. Hedberg, M. Hoekstra, M. C. Evans, A. E. Chin, R. Marcus, D. J. Vugia, K. Smith, S. D. Ahuja, L. Slutsker, and P. M. Griffin. 2004. Farm visits and undercooked hamburgers as major risk factors for sporadic Escherichia coli O157:H7 infection: data from a case-control study in 5 FoodNet sites. Clin. Infect. Dis. 38(Suppl. 3):S271-S278.

18. Kimura, A. C., V. Reddy, R. Marcus, P. R. Cieslak, J. C. MohleBoetani, H. D. Kassenborg, S. D. Segler, F. P. Hardnett, T. Barrett, and D. L. Swerdlow. 2004. Chicken consumption is a newly identified risk factor for sporadic Salmonella enterica serotype Enteritidis infections in the United States: a case-control study in FoodNet sites. Clin. Infect. Dis. 38(Suppl. 3):S244-S252.

19. Kneller, P., and T. Bierma. 1990. Food service certification: measuring the effectiveness of a state program. J. Environ. Health 52:292294.

20. Manning, C., and S. Snider. 1993. Temporary public eating places: food safety knowledge, attitudes, and practices. J. Environ. Health 56:24-28.

21. Oteri, T., and E. Ekanem. 1989. Food hygiene behavior among hospital food handlers. Public Health 103:153-159.

22. Palmer, B. J., J. Hatlen, and B. Jackson, 1975. The implementation and evaluation of management training in a fast food restaurant chain. J. Environ. Health 37:364-368.

23. Research Triangle Institute. 2004. SUDAAN, release 9.0.1. Research Triangle Institute, Research Triangle Park, NC.

24. Rodrigues, L. C., J. M. Cowden, J. G. Wheeler, D. Sethi, P. G. Wall, P. Cumberland, D. S. Tompkins, M. J. Hudson, J. A. Roberts, and P. J. Roderick. 2001. The study of infectious intestinal disease in England: risk factors for cases of infectious intestinal disease with Campylobacter jejuni infection. Epidemiol. Infect. 127:185-193.

25. Schilling, B. J., J. O'Conner, and V. Hendrickson, 2002. State-mandated food safety certification requirements for restaurants: a 2002 review of states. The Food Policy Institute, Rutgers, The State University of New Jersey, New Brunswick. Available at: http:// ageconsearch.umn.edu/bitstream/18177/1/st02sc01.pdf. Accessed 1 November 2007.

26. U.S. Department of Agriculture, Economic Research Service. 2007. Food CPI, prices, and expenditures: food away from home. Available at: http://www.ers.usda.gov/Briefing/CPIFoodAndExpenditures/Data/ table3.htm. Accessed 1 November 2007.

27. U.S. Department of Agriculture, Economic Research Service. 2007. Food CPI, prices and expenditures: foodservice as a share of food expenditures. Available at: http://www.ers.usda.gov/ Briefing/CPIFoodAndExpenditures/Data/table12.htm. Accessed 1 November 2007.

28. U.S. Food and Drug Administration. 2004. FDA report on the occurrence of foodborne illness risk factors in selected institutional food service, restaurant, and retail food store facility types. Available at: www.cfsan.fda.gov/ dms/retrsk2.html. Accessed 1 November 2007.

29. U.S. Food and Drug Administration. 2005. Food code. Available at: http://www.cfsan.fda.gov/ dms/foodcode.html. Accessed 1 November 2007.

30. Wright, J., and L. Feun. 1986. Food service manager certification: an evaluation of its impact. J. Environ. Health 49:12-15. 